\title{
PENGEMBANGAN AKSESIBILITAS TRANSPORTASI PARIWISATA PULAU PRAMUKA KEPULAUAN SERIBU
}

\section{Pramuka Island Tourism Accessibility Transportation Development Of The Thousand Island}

\author{
Dilla Nur Fadilla, Fahrurozy Darmawan \\ Fakultas Pariwisata, Universitas Pancasila Jakarta \\ Srengseng Sawah, Jagakarsa, Jakarta Selatan 12640, Indonesia
}

\begin{abstract}
The development of the tourism industry can not be separated from the development of transportation accessibility. Which although the location of the tour it is very good, the access and transportation is less adequate the tourist visit there will be very limited and just certain tourist groups who visit. The location that the researcher chose to research is the Pramuka islands. With the aim of the strategic planning of the accessibility development in support of Pramuka island tour. The designing of this research uses a mixed method. Basically, this method combines various techniques, philosophy and research design orientation. The collected data will be analyzed by using SWOT analysis followed by compiling an alternative strategy using matrix SWOT for development of tourism transportation accessibility of Pramuka island. Accessibility of tourism transportation of the Pramuka island's view from and towards to the Pramuka island. By looking at the characteristic of the existing transportation system on the Pramuka island by servicing that can get by the tourists while using it. Based on the results of the SWOT analysis raises alternative strategies of making schedules and travel routes in the Pramuka island, making the safety procedure to every existing transportation. Conducting information to the transportation service providers in the importance of transportation licence and quality of human resources in the transportation scope.
\end{abstract}

Keywords: transportation accessibility, tourism transportation, SWOT analysis

\section{PENDAHULUAN}

Pengembangan industri pariwisata tidak dapat dilepaskan dapat pengembangan aksessibilitas transportasi. Yang mana meskipun lokasi wisatanya sangat bagus namun akses dan trasportasinya kurang memadai maka kunjungan wisata ke sana masih amat terbatas, dan hanya golongan wisatawan tertentu yang berkunjung. Banyak lokasi wisata nasional yang tidak berkembang lantaran tidak didukung oleh sarana prasarana yang memadai. Jaringan internet yang buruk tidak menjadi alasan seseorang untuk tidak berkunjung ke suatu lokasi wisata asalkan prasarana dan sarana transportasi-nya bagus.

Untuk menuju ke suatu atraksi wisata pasti ada penghubung antara daerah asal wisatawan menuju daerah tujuan wisata wisatawan yaitu aksesibilitas pariwisata yang mana untuk mencapai suatu daerah tujuan wisata memerlukan akses maupun transportasi.

Dikarenakan transportasi 
penyebrangan merupakan aksesibilitas utama menuju kelurahan Pulau panggang dan sekitarnya termasuk Pulau Pramuka maka perlu dilihat dari keamanan dan kenyamanan wisatawan saat menggunakan kapal tersebut. Menurut C.Jotin khisty dan B. Kent lall (2005) bahwa sitem transportasi yang baik dapat dilihat dari enpat elemen yaitu sarana penghubungnya, terminal,kendaraan serta manajemen dan tenaga kerja. Maka perlu pengecekan kapal secara berkala dimana dapat dilihat layak atau tidaknya untuk beroprasi. Karena faktor keselamatan dan keamanan itu sangatlah penting bagi pengguna dan perlu di perhatikan untuk suatu jasa transportasi yang membawa wisatawan menuju destinasi pariwisata.

Menurut Manheim (1979) ada beberapa atribut-atribut pelayanan Perjalanan jasa transportasi yang hampir sama dan bersaing dalam hal penawaran jasa angkutan seperti price (biaya), Time (waktu), service (kenyamanan dan kesenangan) dan juga safety (keamanan dan keselematan). Tingkat keamanan dan kenyamanan wisatawan saat menggunakan transportasi yang mana digunakan wisatawan untuk berwisata ke Pulau Pramuka dapat berpengaruh terhadap kunjungan wisata ke Pulau Pramuka yang mana disesuaikan dengan keinginan dan kebutuhan penumpang (wisatawan) yang menggunakannya. Maka dari beberapa kutipan diatas penulis memilih judul
"Pengembangan Aksesibilitas Transportasi

Pariwisata Pulau Pramuka Kepulauan

Seribu."

\section{METODE PENELITIAN}

Dalam penelitian ini lokasi penelitian di ambil di pelabuhan menuju Pulau Pramuka yaitu Pelabuhan Marina Ancol, pelabuhan Sunda Kepala, dan Pelabuhan Kali adem/ Muara Angke, Serta Pulau Pramuka dan sekitarnya. Waktu yang dilaksanakan dalam penelitian ini pada bulan Mei-Juli 2017.

Penelitian ini dilakukan dengan menggunakan metode campuran (mixed method) atau hybrid, dan sejenisnya. Awalnyya ditandai oleh beragam definisi, saat ini berkembang definisi yang diarahkan untuk menyatukan berbagai sudut pandang yang pernah ada. Definisi berdasarkan "core characteristics of mixed method research" adalah medote yang menggabungkan berbagai metode, filosofi, dan orientasi desain penelitian (Rully dan Poppy, 2014).

Tehnik penentuan responden dalam penelitian ini adalah seluruh orang yang pernah mengunjungi Pulau Pramuka. Sampel dalam penelitian ini berjumlah 100 responden. Angka tersebut didapat dari teknik slovin dari rekapitulasi kunjungan wisatawan pada tahun 2016.

Analisis data dalam penelitian ini menggunakan Analisis SWOT yang mana analisis SWOT (Stranght, Weaknees, Opportunities, Theath) merupakan alat yang 
efektif dalam membantu mendapatkan strategi pengembangan aksesibilitas transportasi pariwisata dari faktor internal berupa kekuatan dan kelemahan serta faktor eksternal berupa peluang dan ancaman (David, 2008).

\section{HASIL DAN PEMBAHASAN}

Aksesibilitas Transportasi Pariwisata Menuju Pulau Pramuka Sarana penghubung untuk mencapai Pulau pramuka yaitu laut. Pulau Pramuka berada di Kepulauan Seribu yang mana setiap daerah disana di pisahkan oleh laut.

\section{A. Pelabuhan yang melayani perjalanan menuju Pulau Pramuka}

1. Pelabuhan Marina, Ancol

Pelabuhan Marina ini memiliki 23 dermaga yang di miliki atau di sewa oleh beberapa instansi. Untuk dermaga yang dipakai untuk regular yaitu dermaga 16 dan 17 yang di miliki Sealeader yang merupakan suatu perusahaan swasta yang bergerak di pelayanan jasa transportasi Pariwisata. Dan dermaga lainnya dimiliki oleh pulau-pulau resort yang menyediakan kapal sendiri, pihak pemerintahan yang bekerja di Kepulauan Seribu. Pelabuhan ini beroperasi setiap hari yang dapat melayani para wisatawan yang akan berwisata di Kepulauan Seribu.

Di pelabuhan ini dikhususkan untuk para penumpang/ para wisatawan yang akan berlibur ke Kepulauan Seribu. Biaya yang biayarkan menuju Pulau Pramuka dengan tiket regular sebersar Rp. 150.000,/ Orang. Biaya ini sudah termasuk ansuransi keselamatan dari jasamarga. Waktu yang di tempuh menuju Pulau Pramuka dengan menggunakan kapal cepat selama 60 menit jika tidak ada halangan. Fasilitas yang tersedia di Pelabuhan Marina ini itu kantin, ruang tunggu penumpang, minimarket, toilet bersih, musholla, Kantor Travel Sealeader, dan kantor travel Pulau Bidadari.

2. Pelabuhan Sunda Kelapa

Pelabuhan Sunda Kelapa merupakan pelabuhan muat angkut barang yang di peruntunkan untuk kapal-kapal besar. Di pelabuhan ini juga dapat melayani para wisatawan yang akan berwisata ke Kepulauan Seribu dengan Rute Pulau Pramuka, Pulau Tidung dan Pulau Kelapa. Pelabuhan ini beroprasi setiap hari namun untuk keberangkatan kapal wisata hanya pada hari senin, Rabu dan Sabtu saja. Ini di sebabkan karena keterbatasan kapal yang tersedia. Fasilitas yang ada di pelabuhan ini toilet, warung, musholla namun jaraknya cukup jauh dengan dermaga keberangkatan.

Pelabuhan ini dapat digunakan untuk muat angkut barang tapi ada juga kapal penumpang yang disediakan Kemenhub untuk transportasi pariwisata menuju Pulau 
Pramuka, Pulau Tidung dan Pulau Pramuka. Biaya yang di bayarkan jika regular itu sebesar Rp.20.000,- sampai Rp.30.000,-/ Orang sudah termasuk asuransi. Dengan waktu tempuh menuju Pulau Pramuka selama 180 menit.

3. Pelabuhan Muara Angke

Pelabuhan Muara Angke memiliki luas 65 ha, terletak di Muara Angke. Secara administratif terletak di Kelurahan Pluit, Kecamatan Penjaringan, Kotamadya Jakarta Utara. Pelabuhan ini melayani perjalanan hampir ke seluruh pulau di Kepulauan Seribu termasuk Pulau Pramuka. Pelabuhan ini beroprasi setiap hari untuk melayani para wisatawan maupun masyarakat Kepulauan Seribu.

Untuk menuju ke Pulau Pramuka melalui pelabuhan Muara angke Biaya yang ditawarkan untu regularsebesar Rp.40.000 / Orang, sampai Rp.100.000,sesuai jenis kapal yang akan digunakan. Berikut merupakan daftar Kapal Motor yang terdaftar di Dinas Perhubungan DKI Jakarta yang melayani wisatawan untuk berwisata ke Pulau Pramuka. Waktu tempuh menuju Pulau Pramuka selama 90120 menit sesuai dengan jenis kapal apa yang di gunakan. Fasilitas yang ada di pelabuhan ini toilet dan musolla untuk warung, kantin dan ATM center berada di luar pintu masuk pelabuhan.

Dari jumlah armada yang ada transportasi menuju pulau pramuka dapat membawa wisatawan ke Pulau Pramuka dengan jumlah yang banyak. Namun disayangkan frekuensi keberangkatan menuju Pulau Pramuka setiap harinya hanya satu kali keberangkatan terkecuali saat high season frekuensi keberangkatan ditambahkan.

\section{B. Aksesibilitas Transportasi Pariwisata Di Pulau Pramuka}

Pulau Pramuka memiliki 4 dermaga yaitu dermaga utama, dermaga PI (Pelelangan Ikan), Dermaga Kabupaten Kepulauan seribu, dan Dermaga Dinas Perhubungan. Keempat dermaga tersebut melayani arus kedatangan dan keberangkatan setiap wisatawan yang datang berwisata ke Pulau Pramuka. Dermaga Utama biasanya di gunakan untuk kapal motor besar, dan perahu motor (kapal ojek) lintas pulau yang reguler. Dermaga Perhubungan dipakai oleh kapal besar yang memerlukan kedalaman air laut yang sangat dalam. Dermaga Kabupaten diperuntunkan untuk tamu-tamu pemerintahan yang menyewa kapal sendiri. Dan yang terakhir dermaga PI digunakan untuk kapal-kapal nelayan pencari ikan namun jika sore dipakai untuk kapal cepat regular yang kapasitas dibawah 30 orang. Aksesibilitas jalan di Pulau Pramuka itu non aspal terlihat jalanan perkampungan biasa dengan kondisi baik. Namun jalan di pulau ini teruntuk semua penguna baik untuk pejalan kaki, motor dan 
sepeda. Berikut data moda Transportasi yang ada di Pulau Pramuka.

Sarana transportasi di Pulau Pramuka ada dua moda transportasi yaitu transportasi darat dan penyebrangan. Transportasi darat di Pulau Pramuka hanya terdapat motor, motor roda tiga (odong-odong), dan sepeda yang dapat digunakan wisatawan berkeliling Pulau Pramuka. Wisatawan yang berkunjung ke Pulau Pramuka biasanya melakukan wisata berkeliling pulau yang berdekatan dengan Pulau Pramuka dapat menggunakan transportasi perahu motor. Di Pulau Pramuka terdapat moda transportasi yang regular dan carter. Jenis tranportasi carter hanya berlaku untuk sepeda dan perahu motor saja, jika carter wisatawan dapat menggunakan sesuai dengan kebutuhan wisatawan.

\section{Wisata di Pulau Pramuka}

Wisatawan dapat melakukan wisata dalam pulau dengan menggunakan sarana transportasi seperti motor bak atau yang sering di sebut dengan odong-odong dengan mengeluarkan biaya sebesar Rp. 5000,wisatawan dapat berkeliling Pulau Pramuka. Atau bisa juga dengan menyewa sepeda dengan biaya Rp. 20.000,- untuk satu hari, namun tempat penyewaan sepeda di Pulau Pramuka cukup sulit di temukan. Atraksi yang ada di Pulau Pramuka antara lain yaitu : RPTRA (Ruang Publik Terpadu Ramah Anak) Taman Tanjung Elang, yang berkunjung ke Pulau Pramuka, Konservasi
Penyu Sisik, Konservasi Mangrove, Taman mini bawah laut, dan Plaza Pulau Pramuka.

\section{Wisata sekitar Pulau Pramuka}

Ketika di Pulau Pramuka wisatawan dapat melakukan wisata bahari sampai ke beberapa pulau di sekitar Pulau Pramuka. Hal ini dikarenakan pulau reklamasi atraksi wisata bahari di Pulau Pramuka semakin berkurang. Untuk melakukan perjalanan wisata kebeberapa Pulau sekitar Pulau Pramuka dapat menggunakan perahu ojek. Perahu ojek milik masyarakat setempat ini dengan rute regular Pulau Karya, Pulau Panggang, dan Nusa Keramba dengan biaya Rp.5.000,- per orang. Tapi jika ingin berkunjung ke pulau lain yang berdekatan dengan Pulau Pramuka wisatawan dapat carter perahu motor dengan biaya sebesar Rp. 250.000,- per perahu dengan kapasitas maksimal 12 Orang sesuai Rute permintaan wisatawan. Berikut merupakan Pulau-Pulau yang menjadi atraksi bagi wisatawan yang berdekatan dengan Pulau Pramuka yaitu : Pulau Panggang, Pulau Karya, Nusa Keramba, Pulau Semak Daun, Pulau air dan Pulau Gosong Pandan.

\section{Pelayanan Jasa Transportasi Pulau Pramuka}

Menurut Manheim (1979) menyatakan bahwa perjalanan jasa transportasi ada 4 komponen yaitu waktu, biaya, kesenangan dan kenyamanan dan keselamatan dan keamanan berikut ini hasil dari kuesioner yang di sebar kepada wisatawan yang menggunakan 
transportasi untuk melakukan perjalanan wisata di Pulau Pramuka.

1. Biaya (Price)

Dari segi biaya jasa transportasi yang tersedia menuju maupun di Pulau Pramuka cukup terjangkau. Transportasi yang tersedia juga bermacam-macam jenis dan biayanya sesuai dengan fasilitas yang diberikan.

2. Waktu (Time)

Waktu untuk mendapatkan transportasi menuju Pulau Pramuka sesuai jadwal yang tertera tetapi jika di saat highseason ada penambahan jam perjalanan.

3. Kesenangan dan Kenyamanan (Service)

Fasilitas yang diterima sesuai dengan jenis dan biaya yang dibayarkan. Terdapat hiburan di beberapa transportasi untuk membuat nyaman sang pengguna.

4. Keselamatan dan Keamaan (Safety)

Dalam menggunakan transportasi menuju maupun di Pulau Pramuka yang kebanyakan menggunakan transportasi perairan fasilitas keselamatan yang tersedia yaitu sepeti pelampung, pemadam kebakaran dan P3K yang tersedia di kapal.Serta surat izin berlayar dari otoritas pelabuhan untuk membuat rasa aman penumpang.

Volume 6 No.2 Desember 2018, ISSN: 2339-1987

\section{Managemen dan Tenaga Kerja}

Pihak pihak yang terlibat dalam aksesibilitas transportasi pariwisata di Pulau Pramuka sebagai Berikut :

1. Suku Dinas Perhubungan Kabupaten Kepulauan Seribu

Bertugas melaksanakan pembinaan, pembangunan, pengelolaan, pengendalian dan mengkoordinasikan kegiatan di bidang perhubungan darat, laut dan udara.

2. Syahbandar adalah pejabat pemerintah di pelabuhan yang diangkat oleh Menteri dan memiliki kewenangan tertinggi untuk menjalankan dan melakukan pengawasan terhadap dipenuhinya ketentuan peraturan perundang-undangan untuk menjamin keselamatan dan keamanan pelayaran. (UU No.17 Tahun 2008)

3. Awak Kapal

Awak Kapal adalah orang yang bekerja atau dipekerjakan di atas kapal oleh pemilik atau operator kapal untuk melakukan tugas di atas kapal sesuai dengan jabatannya yang tercantum dalam buku sijil.

- Nakhoda adalah salah seorang dari Awak Kapal yang menjadi 
pemimpin tertinggi di kapal dan

mempunyai wewenang dan tanggung jawab tertentu sesuai dengan ketentuan peraturan perundang-undangan.

- Dan Awak Buah Kapal adalah Awak Kapal selain Nakhoda.

(UU No.17 Tahun 2008)

4. Pengusaha Jasa Trasnportasi

Memberikan pelayanan,

kemudahan, dan kenyamanan kepada masyarakat untuk memperlancar aktivitas produksi maupun konsumsi. Jasa yang dihasilkan bersifat abstrak tapi bisa dirasakan manfaatnya oleh konsumen.

- Pemilik Penyewaan sepeda

Di Pulau Pramuka sebenarnya tidak terdapat tempat penyewaan sepeda secara khusus. Namun sepeda pemilik homestay dapat di sewakan. Jadi jumlah sepeda yang dapat di sewa di Pulau Pramuka sangat sedikit karena masyarakat disana juga menjadikan sepeda menjadi trasnportasi seharisehari mereka.

5. Supir Motor roda tiga

Seseorang yang mengemudikan motor yang beroda tiga yang dapat membawa wisatawan berkeliling di Pulau Pramuka.

Di Pulau Pramuka sebenarnya tidak terdapat tempat penyewaan sepeda secara khusus. Namun sepeda pemilik homestay dapat di sewakan. Jadi jumlah sepeda yang dapat di sewa di Pulau Pramuka sangat sedikit karena masyarakat disana juga menjadikan sepeda menjadi trasnportasi sehari-sehari mereka.

Berikut ini merupakan peraturan yang mengatur jalannya aksesibilitas transportasi pariwisata Pulau Pramuka:

1. Peraturan Pemerintah nomor 47 tahun 1957 tentang perizinan pelayaran

2. Undang-Undang no.17 tahun 2008 tentang Pelayaran

3. Peraturan daerah provinsi daerah khusus ibukota Jakarta nomor 5 tahun 2014 tentang transportasi

4. Peraturan Menteri 12 tahun 2016 tentang Jasa Pengurusan Transportasi

\section{Analisis SWOT}

Analisis SWOT berpatokan pada 4 elemen dari 2 faktor yaitu faktor internal kekuatan dan kelemahan dan faktor eksternal peluang 
dan ancaman. Pengisisan setiap faktor

ditemukan dari hasil penelitian mengenai kondisi eksisting keadaan yang sebenarnya yang terdapat dari hasil wawancara, kuesioner dan data-data yang di temukan di lapangan.

Tabel 1. Faktor Internal

\begin{tabular}{|c|c|}
\hline \multicolumn{2}{|c|}{ Faktor Internal } \\
\hline Kekuatan (Strenght) & Kelemahan (Weakness) \\
\hline 1. Ketepatan waktu perjalanan & 1. Kebersihan dalam moda transportasi \\
\hline 2. Harga Transportasi murah & masih kurang \\
\hline 3. Setiap kapal yang akan berlayar wajib & 2. Sistem transportasi darat masih kurang \\
\hline berlayar) demi keselamatan & 3. Teknologi navigasi belum canggih \\
\hline $\begin{array}{l}\text { 4. Kapasitas pelabuhan di Pulau Pramuka } \\
\text { dapat menampung banvak kapal }\end{array}$ & $\begin{array}{l}\text { 4. Belum semua nakhoda dan pengemudi } \\
\text { motor memiliki SKK dan SIM }\end{array}$ \\
\hline $\begin{array}{l}\text { 5. Setiap kapal menuju Pulau Pramuka } \\
\text { memiliki alat keselamatan minimal }\end{array}$ & $\begin{array}{l}\text { 5. Kurangnya kualitas SDM dalam } \\
\text { pelayanan jasa transportasi }\end{array}$ \\
\hline pelampung dan pemadam kebakaran & 6. Belum adanya prosedur keselamatan \\
\hline 6. Transportasinya dapat menampung & ketika saat menggunakan moda \\
\hline $\begin{array}{l}\text { banyak wisatawan untuk setiap } \\
\text { harinya }\end{array}$ & $\begin{array}{l}\text { transportasi, baik itu secara tulisan } \\
\text { maupun lisan. }\end{array}$ \\
\hline
\end{tabular}

Tabel 2. Faktor Eksternal

\begin{tabular}{|l|l|}
\hline \multicolumn{4}{|c|}{ Faktor Eksternal } \\
\hline Peluang (Opportunities) & Ancaman (Thearts) \\
\hline $\begin{array}{l}\text { 1. Dukungan Pemerintahan Pusat bahwa } \\
\text { Kepulauan Seribu merupakan 10 }\end{array}$ & $\begin{array}{l}\text { 1. Tranportasi perairan menjadi transportasi } \\
\text { utama di Pulau Pramuka yang dapat } \\
\text { menjadi pemanfaatan oknum-oknum }\end{array}$ \\
$\begin{array}{ll}\text { 2. Banyaknya pelayaran Kepulauan Seribu } \\
\text { yang transit di Pulau Pramuka }\end{array}$ & $\begin{array}{l}\text { 2. Kebijakan Pemerintah dalam kenaikan } \\
\text { BBM }\end{array}$ \\
$\begin{array}{ll}\text { 3. Terdapat landasan udara di pulau } \\
\text { panjang }\end{array}$ & $\begin{array}{l}\text { 3. Faktor cuaca tak menentu di Kepulauan } \\
\text { Seribu }\end{array}$ \\
$\begin{array}{ll}\text { 4. Pulau Pramuka berdekatan dengan } \\
\text { pulau-pulau } \\
\text { dibandingkan pulau pemukiman yang } \\
\text { lain }\end{array}$ & $\begin{array}{l}\text { 4. Belum adanya ketentuan tarif yang pasti } \\
\text { pada angkutan transportasi yang ada di } \\
\text { Pulau Pramuka }\end{array}$ \\
\hline
\end{tabular}

Setelah menentukan faktor internal dan faktor eksternal maka masuk ke pembobotan dan rating di setiap indikator yang ada.

Tabel 3. Pembobotan Internal

\begin{tabular}{|c|l|c|c|c|}
\hline No & \multicolumn{1}{|c|}{ Kekuatan (stranght) } & Bobot & Rating & Total \\
\hline 1. & Ketepatan waktu perjalanan & 0,06 & 3 & 0,18 \\
\hline 2. & Harga Transportasi murah & 0,09 & 4 & 0,36 \\
\hline
\end{tabular}




\begin{tabular}{|c|c|c|c|c|}
\hline 3. & $\begin{array}{l}\text { Setiap kapal yang akan berlayar wajib } \\
\text { memiliki SPB (surat persetujuan berlayar }\end{array}$ & 0,11 & 2 & 0,22 \\
\hline 4. & $\begin{array}{l}\text { Kapasitas pelabuhan di Pulau Pramuka } \\
\text { dapat menampung banyak kapal }\end{array}$ & 0,10 & 3 & 0,30 \\
\hline 5. & $\begin{array}{l}\text { Setiap kapal menuju Pulau Pramuka } \\
\text { memiliki alat keselamatan minimal } \\
\text { pelampung dan pemadam kebakaran }\end{array}$ & 0,08 & 4 & 0,32 \\
\hline 6 & $\begin{array}{l}\text { Transportasinya dapat menampung } \\
\text { banyak wisatawan untuk setiap harinya }\end{array}$ & 0,05 & 3 & 0,15 \\
\hline \multicolumn{2}{|r|}{ Total Kekuatan $(S)$} & $\mathbf{0 , 4 9}$ & & $\mathbf{1 , 5 3}$ \\
\hline No & Kelemahan (weakness) & Bobot & Rating & Total \\
\hline 1. & $\begin{array}{l}\text { Kebersihan dalam moda transportasi } \\
\text { masih kurang }\end{array}$ & 0,08 & 2 & 0,16 \\
\hline 2. & $\begin{array}{l}\text { Sistem transportasi darat masih kurang } \\
\text { perhatian }\end{array}$ & 0,11 & 3 & 0,33 \\
\hline 3. & Teknologi navigasi belum canggih & 0,10 & 4 & 0,40 \\
\hline 4. & $\begin{array}{l}\text { Belum semua nakhoda dan pengemudi } \\
\text { motor memiliki SKK dan SIM }\end{array}$ & 0,06 & 3 & 0,18 \\
\hline 5. & $\begin{array}{l}\text { Kurangnya kualitas SDM dalam } \\
\text { pelayanan transportasi }\end{array}$ & 0,09 & 4 & 0,36 \\
\hline 6. & $\begin{array}{l}\text { Belum adanya prosedur keselamatan } \\
\text { ketika saat menggunakan moda } \\
\text { transportasi, baik itu secara tulisan } \\
\text { maupun lisan. }\end{array}$ & 0,07 & 3 & 0,21 \\
\hline \multicolumn{2}{|r|}{ Total Kelemahan $(\mathrm{W})$} & $\mathbf{0 , 5 1}$ & & 1.64 \\
\hline \multicolumn{2}{|r|}{ Total Keseluruhan } & 1,00 & & $-0,11$ \\
\hline
\end{tabular}

Tabel 4. Pembobotan Eksternal

\begin{tabular}{|c|c|c|c|c|}
\hline No & Peluang (Opportunities) & Bobot & Rating & Total \\
\hline 1. & $\begin{array}{l}\text { Dukungan Pemerintahan Pusat bahwa } \\
\text { Kepulauan Seribu merupakan } 10 \text { destinasi } \\
\text { prioritas di Indonesia }\end{array}$ & 0,16 & .3 & 0,48 \\
\hline 2. & $\begin{array}{l}\text { Banyaknya pelayaran Kepulauan Seribu } \\
\text { yang transit di Pulau Pramuka }\end{array}$ & 0,11 & 4 & 0,44 \\
\hline 3. & Terdapat landasan udara di pulau panjang & 0,12 & 3 & 0,36 \\
\hline 4 & $\begin{array}{l}\text { Pulau Pramuka berdekatan dengan pulau- } \\
\text { pulau wisata lainnya dibandingkan pulau } \\
\text { pemukiman yang lain }\end{array}$ & 0,14 & 4 & 0,56 \\
\hline & Total Peluang $(\mathbf{O})$ & $\mathbf{0 , 5 3}$ & & 1,84 \\
\hline No & Ancaman (Threats) & Bobot & Rating & Total \\
\hline
\end{tabular}




\begin{tabular}{|l|l|c|c|c|}
\hline 1. & $\begin{array}{l}\text { Tranportasi perairan menjadi transportasi } \\
\text { utama di Pulau Pramuka yang dapat } \\
\text { menjadi pemanfaatan oknum-oknum }\end{array}$ & 0,09 & 4 & 0,36 \\
\hline 2. & $\begin{array}{l}\text { Kebijakan Pemerintah dalam kenaikan } \\
\text { BBM }\end{array}$ & 0,13 & 4 & 0,52 \\
\hline 3. & $\begin{array}{l}\text { Faktor cuaca tak menentu di Kepulauan } \\
\text { Seribu }\end{array}$ & 0,14 & 3 & 0,42 \\
\hline 4 & $\begin{array}{l}\text { Belum adanya ketentuan tarif yang pasti } \\
\text { pada angkutan transportasi yang ada di } \\
\text { Pulau Pramuka }\end{array}$ & 0,11 & 3 & 0,33 \\
\hline \multicolumn{1}{|c|}{ Total Ancaman (T) } & $\mathbf{0 , 4 7}$ & $\mathbf{1 , 0 0}$ & $\mathbf{0 , 2 1}$ \\
\hline Total Keseluruhan & $\mathbf{1 , 0 3}$ \\
\hline
\end{tabular}

Hasil dari pembobotan di atas di ketahui bahwa $\mathrm{x}$ yaitu dari faktor internal (kekuatan-kelemahan) sebesar -0,11 dan hasil dari y yaitu dari faktor eksternal (kesempatanancaman) yaitu 0,21. Maka dari hasil pembobotan antara faktor internal dengan faktor eksternal maka dapat dibuat diagram dan dapat diketahui dititik kuadran keberapa strategi pengembangan transportasi pariwiwsata Pulau Pramuka.

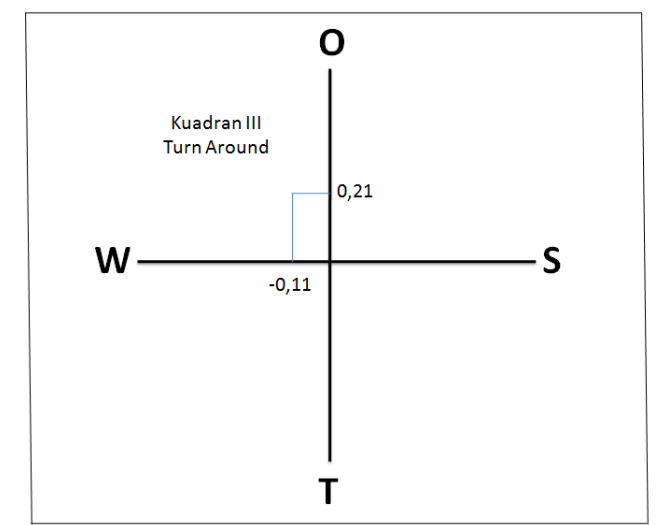

Gambar 1. Diagram Analisis SWOT

Berdasarkan hasil pembobotan antara
IFE dan EFE diketahui bahwa sumbu $\mathrm{x}$ kekuatan $(\mathrm{S})$ - kelemahan $(\mathrm{W})=-0,11$ sumbu y peluang $(\mathrm{O})$ - ancaman $(\mathrm{T})=0,21$

Jadi, jika dilihat dari analisis SWOT (gambar 4.13) Berada pada kuadran III . Kuadran III artinya strategi yang harus diterapkan adalah memanfaatkan peluang untuk mengurangi kelemahan agar perusahaan tetap stabil. Disini perlunya meminimalkan kelemahan sekecil mungkin dengan menggunakan peluang-peluang yang ada. Kondisi ini berarti turn around dimana pasar sangat besar namun terkendala akan faktor intenternalnya yang lemah.

Untuk mengetahui keterkaitan antar strategi berdasarkan pembobotan SWOT maka dapat dilakukan dengan kombinasi strategi antara internal dan eksternal yang di sajikan secara matriks SWOT seperti di dalam tabel 4.21 yang menjelaskan kombinasi diantara dua faktor untuk menemukan strategi yang cocok untuk pengembangan aksesibilitas transportasi Pulau Pramuka. 
Tabel 5. Matriks SWOT

\begin{tabular}{|c|c|c|}
\hline Analisis SWOT & Kekuatan (Stranght) & Kelemahan (Weakness) \\
\hline EFES & $\begin{array}{l}\text { 1. Ketepatan waktu } \\
\text { perjalanan } \\
\text { 2. Harga Transportasi murah } \\
\text { 3. Setiap kapal yang akan } \\
\text { berlayar wajib memiliki } \\
\text { SPB (surat persetujuan } \\
\text { berlayar) demi } \\
\text { keselamatan } \\
\text { 4. Kapasitas pelabuhan di } \\
\text { pulau pramuka dapat } \\
\text { menampung banyak kapal } \\
\text { 5. Setiap kapal menuju } \\
\text { Pulau Pramuka memiliki } \\
\text { alat keselamatan minimal } \\
\text { pelampung dan pemadam } \\
\text { kebakaran } \\
\text { Transportasinya dapat } \\
\text { menampung banyak } \\
\text { wisatawan untuk setiap } \\
\text { harinya }\end{array}$ & $\begin{array}{l}\text { 1. } \begin{array}{l}\text { Kebersihan dalam moda } \\
\text { transportasi masih kurang }\end{array} \\
\text { 2. Sistem transportasi darat } \\
\text { masih kurang perhatian } \\
\text { 3. Teknologi navigasi } \\
\text { belum canggih } \\
\text { 4. Belum semua nakhoda } \\
\text { dan pengemudi motor } \\
\text { memiliki SKK dan SIM } \\
\text { 5. Kurangnya kualitas SDM } \\
\text { dalam pelayanan jasa } \\
\text { transportasi } \\
\text { 6elum adanya prosedur } \\
\text { keselamatan ketika saat } \\
\text { menggunakan moda } \\
\text { transportasi, baik itu } \\
\text { secara tulisan maupun } \\
\text { lisan. }\end{array}$ \\
\hline Peluang (Opportunities) & Strategi (SO) & Strategi (WO) \\
\hline $\begin{array}{l}\text { 1. Dukungan } \\
\text { Pemerintahan Pusat } \\
\text { bahwa Kepulauan } \\
\text { Seribu merupakan } \\
10 \text { destinasi prioritas } \\
\text { di indonesia } \\
\text { 2. Banyaknya } \\
\text { pelayaran Kepulauan } \\
\text { Seribu yang transit } \\
\text { di Pulau Pramuka } \\
\text { 3erdapat landasan } \\
\text { udara di pulau } \\
\text { panjang } \\
\text { 4. Pulau Pramuka } \\
\text { berdekatan dengan } \\
\text { pulau-pulau wisata } \\
\text { lainnya } \\
\text { dibandingkan pulau } \\
\text { pemukiman yang } \\
\text { lain. }\end{array}$ & 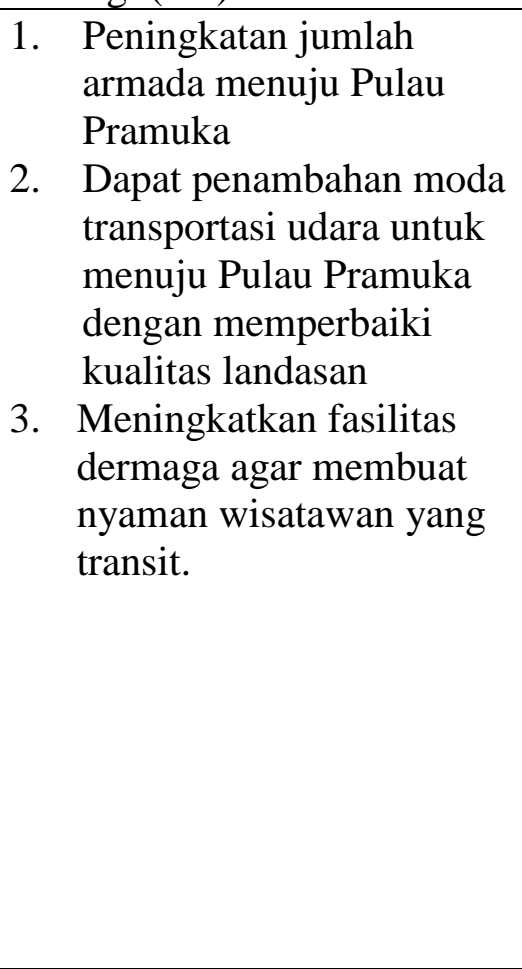 & $\begin{array}{l}\text { 1. Meningkatkan sistem } \\
\text { moda transportasi darat } \\
\text { dari segi tarif, rute, dan } \\
\text { pengawasan } \\
\text { 2. Mengadakan penyuluhan } \\
\text { kepada semua nakhoda, } \\
\text { ABK dan para pihak jasa } \\
\text { transportasi mengenai } \\
\text { SKK dan pelayanan jasa } \\
\text { transportasi } \\
\text { 3. Pembuatan prosedur } \\
\text { keselamatan bagi para } \\
\text { penumpang } \\
\text { 4. Meningkatan kebersihan } \\
\text { moda transportasi } \\
\text { minimal terdapat tempat } \\
\text { sampah. }\end{array}$ \\
\hline Ancaman (Threats) & Strategi (ST) & Strategi (WT) \\
\hline
\end{tabular}




\begin{tabular}{|c|c|c|}
\hline $\begin{array}{l}\text { 1. Tranportasi peraiean } \\
\text { menjadi transportasi } \\
\text { utama di Pulau } \\
\text { Pramuka yang dapat } \\
\text { menjadi } \\
\text { pemanfaatan oknum- } \\
\text { oknum } \\
\text { 2. Kebijakan } \\
\text { Pemerintah dalam } \\
\text { kenaikan BBM } \\
\text { 3. Faktor cuaca tak } \\
\text { menentu di } \\
\text { Kepulauan Seribu } \\
\text { 4. Belum adanya } \\
\text { ketentuan tarif yang } \\
\text { pasti pada angkutan } \\
\text { transportasi yang ada } \\
\text { di Pulau Pramuka }\end{array}$ & $\begin{array}{l}\text { 1. Penerapan prosedur jasa } \\
\text { transportasi untuk semua } \\
\text { armada dalam segi tarif, } \\
\text { rute, jadwal pp. } \\
\text { 2. Dilakukannya } \\
\text { Pengawasan yang rutin } \\
\text { terhadap transportasi } \\
\text { yang ada di Pulau } \\
\text { Pramuka agar terhindar } \\
\text { dari oknum-oknum yang } \\
\text { tak bertanggung jawab. }\end{array}$ & $\begin{array}{l}\text { 1. Peningkatan sistem } \\
\text { navigasi yang terus di } \\
\text { perbaiki } \\
\text { 2. } \text { Bentuk dan terapkan } \\
\text { standar oprasi tanggap } \\
\text { darurat kecelakaan atau } \\
\text { prosedur keselamatan } \\
\text { 3. SDM diberikan } \\
\text { pengusaan tentang } \\
\text { pelayanan jasa } \\
\text { transportasi agar dapat } \\
\text { melayani pengguna moda } \\
\text { transportasi dengan baik }\end{array}$ \\
\hline
\end{tabular}




\section{KESIMPULAN}

- Kondisi eksisting aksesibilitas transportasi pariwisata Pulau Pramuka bahwa Aksesibilitas transportasi menuju. Pulau Pamuka dapat menggunakan moda transportasi kapal cepat, kapal tradisional dan kapal printis. Kapal cepat lebih diminati oleh wisatawan yang menuju Pulau Pramuka. Terminal yang melayani penyebrangan menuju Pulau Pramuka adalah Pelabuhan Marina, SundaKelapa dan Muara Angke. Setiap nakhoda yang membawa kapal 30 mil keatas wajib memiliki SKK (surat keterangan kecakapan) dan kapal yang akan berlayar wajib memiliki SPB (surat persetujuan berlayar) yang dikeluarkan oleh Syahbandar dan Otoritas Pelabuhan. Kondisi ekisting aksesibilitas transportasi Pariwisata di Pulau Pramuka wisatawan yang berwisata di Pulau Pramuka dapat menggunakan moda transportasi darat yaitu motor roda tiga, motor dan sepeda untuk berkeliling Pulau Pramuka menikmati atraksi wisata yang ada di dalam pulau. Bila ingin berwisata mengunjungi pulau-pulau di sekitar Pulau Pramuka dapat menggunakan transportasi perahu motor yang disediakan oleh masyarakat Pulau Pramuka utuk menikmati pariwisata bahari. Pihak-pihak yang berada di dalamnya yaitu Dinas Perhubungan, Syahbandar, Pengusaha jasa transportasi, dan Suku Dinas Pariwisata dan kebudayaan kabupaten administrasi Kepulauan Seribu . transportasi setiap nakhoda yang membawa kapal 30 mil wajib memiliki SKK (surat keterangan kecakapan) dan kapal yang akan berlayar wajib memiliki
SPB (surat persetujuan berlayar) yang dikeluarkan oleh syahbandar dan otoritas pelabuhan.

- Strategi pengembangan yang dapat dilakukan untuk:

a. Meningkatkan sistem moda transportasi darat dari segi tarif, rute, dan pengawasan sistem transportasi Pulau Pramuka Kemudian rute pariwisata transportasi darat di pulau pramuka belum ditentukan, ketika naik kendaraan umum disana yaitu motor roda tiga (odong-odong) penumpang akan diantar ke tempat tujuan dan jika didalamnya tertapat penumpang lain itu saling mengantar satu sama lain sesuai dengan penumpang yang dahulu naik maka pengembangan yang dilakukan pembuatan rute transportasi umum.

b. Mengadakan penyuluhan kepada pihakpihak yang terkait dalam jasa transportasi baik penyedia jasa transportasi maupun para pegawai yang melayani jasa transportasi.

c. Pembuatan prosedur keselamatan bagi para penumpang baik secara tulisan maupun lisan agar mempermudah pengguna jasa transportasi jikalau dalam keadaan yang tidak diinginkan.

d. Meningkatan kebersihan moda transportasi minimal terdapat tempat sampah. Agar membuat nyaman pengguna jasa transportasi saat menggunakannya. Dan adanya jadwal pembersihan moda transportasi secara rutin dilakukan penyedia jasa transportasi agar moda transportasi yang ada tetap terjagakebersihannya. 
SARAN

Dalam rangka pengembanagn aksesibilitas transportasi pariwisata ada beberapa yang perlu di perhatikan.

1. Pelaku usaha transportasi seharusnya dapat memenuhi ketentuan aturan hukum yang berlaku dengan melengkapi surat-surat kendaraan serta perizinan yang ada dan untuk para pengemudinya harus memiliki standar pengemudi seperti kepemilikan SKK dan SIM demi keamanan dan kenyamanan para pengguna transportasi.

2. Untuk pihak pihak terkait Syahbandar untuk mempertetat lagi perizinan berlayar kapal. Kapal yang bisa berlayar harus benar-benar lulus perizinan untuk

\section{DAFTAR PUSTAKA}

Budiartha Nyoman. 2011. Peranan Transportasi dalam Pariwisata Studi Kasus: Pemilihan Daerah Tujuan Wisata (Dtw/Destinasi) Oleh Wisatawan di Bali. Jurnal Tehnik Sipil, vol.15. no.2

David Fred. 2008. Managemen Strategis, Ed. 12. Terjemahan oleh Dono Sunardi. 2010. Jakarta (ID) : Salemba Empat

Gunawan Harry. 2014. Pengantar Transportasi dan Logistik. Jakarta meminimalisir kecelakan. Dinas Perhubungan lebih meningkatkan kualitas pelabuhan dari segi fasilitas yang ada dan sistem navigasi yang harusnya terus berjalan. Dan Suku Dinas pariwisata kabupaten kepulauan seribu membuat peta wisata untuk mempemuda wisatawan dalam berwisata di Pulau Pramuka.

3. Pembuatan kesesuian tarif pada transportasi umum yang ada di Pulau Pramuka untuk menghindari dari kecurangan-kecurangan oknum-oknum yang tak bertanggung jawab.

4. Membuat prosedur keselamatan untuk memberikan pengetahuan keselamatan kepada para pengguna transportasi jika terjadi kejadian yang tidak diinginkan.

Indrawan R, Yaniawati P. 2014. Metodelogi Penelitian Kuantitatif, Kualitatif, dan campuran untuk Managemen, Pengembangan dan Pendididkan. Bandung (ID) : Refika Aditama

Jusna 2016. Peranan Transportasi Laut dalam Menunjang Arus Barang dan Orang di Kecamatan Maligono Kabupaten Muna [Skripsi] Kendari (ID) : Universitas Haluoloue

Khisty CJ \& Lall BK. 2005. Dasar - Dasar 
Rekayasa Transportasi. Jakarta. Erlangg

Manheim, M.L. (1979). Fundamentals of Transportation Systems Analysis, Vol. 1: Basic Concepts. Cambridge, MA: MIT Press

Sugiyono. 2008. Metode Penelitian Kuantitatif Kualitatif dan campuran. Bandung

(ID):

Alfabeta

Sugiyono. 2009. Metode Penelitian Kuantitatif dan Kualitatif. Bandung (ID): Alfabeta

Tami, OZ. 2000. Perencanaan dan Pemodelan Transportasi. Ed. 2. Bandung (ID). Penerbit ITB 